\title{
Sexual and Urinary Disorders after Treatment of Rectal Cancer by Radiotherapy and Surgery at the Dantec University Hospital of Dakar
}

\author{
Mouhamadou Bachir Ba1, Papa Macoumba Gaye1, Karim Konate², Ahmadou Dem² \\ ${ }^{1}$ Radiotherapy Department, Dalaljamm Hospital, Dakar, Senegal \\ ${ }^{2}$ Joliot Curie Institute, Dakar, Senegal \\ Email: macoumba.gaye@gmail.com,mbbachir21@gmail.com, Adehdem@gmail.com
}

How to cite this paper: Ba, M.B., Gaye, P.M., Konate, K. and Dem, A. (2020) Sexual and Urinary Disorders after Treatment of Rectal Cancer by Radiotherapy and Surgery at the Dantec University Hospital of Dakar. Journal of Cancer Therapy, 11, 332-338.

https://doi.org/10.4236/jct.2020.115027

Received: September 30, 2018

Accepted: May 16, 2020

Published: May 19, 2020

Copyright $\odot 2020$ by author(s) and Scientific Research Publishing Inc. This work is licensed under the Creative Commons Attribution International License (CC BY 4.0).

http://creativecommons.org/licenses/by/4.0/

\begin{abstract}
We performed a descriptive retrospective study of sexual and urinary disorders after treatment of rectal cancer by radiotherapy and/or surgery at the Dantec University Hospital in Dakar from 2008 to 2015. The objective of the study was to evaluate these sexual and urinary complications and the factors influencing it. We have collected 50 patients. The average age of is 55.7 years with a sex ratio of 0.78 . The dominant clinical signs are rectorrhagia (66.0\%). Endoscopy (94.0\% of patients) showed an ulcerative-budding appearance in $84.0 \%$ of cases. The preferred location was the lower rectum $66.0 \%)$. The predominant histologic type is adenocarcinoma lieberkunien (82.0\%). Computed tomography is performed in $78 \%$ of cases and MRI in $30 \%$. Stage III accounts for $70.0 \%$ of cases. Thirty-two patients (64.0\%) were treated with conventional 2-beam $2 \mathrm{D}$ radiation therapy with or without chemotherapy. The total dose of $46 \mathrm{~Gy}$ in 23 sessions was the most used, found in 22 patients; $30 \mathrm{~Gy}$ in 10 sessions in 9 cases. And 16 Gy in 10 sessions, found in 1 case. Surgery performed was abdominoperineal amputation (58.0\%) and conservative surgery (42.0\%). We note a complete response in $28.0 \%$ of patients; $8.0 \%$, an increase of $16.0 \%$ and a stabilization of $4.0 \%$. The sexual disorders are more important after radiotherapy compared to non-irradiated patients: $31.3 \%$ vs $5.6 \%(\mathrm{p}=0.035)$. We observe respectively that $2 \%, 6 \%$ and $8 \%$ of our patients had urinary disorders in the form of acute retention, urinary incontinence, and urinary burning. Patient follow-up time was between 0 and 42.83 months with an estimated average of $34.9 \pm 3.37$. The evolution is marked at 6 months by a persistence of sexual disorders in $63.8 \%$ of cases and urinary dysfunction in $4 \%$ of cases.
\end{abstract}

\section{Keywords}

Sexual, Urinary Disorders After, Rectal Cancers 


\section{Introduction}

Surgery is the cornerstone of rectal cancer treatment. It consists of total removal of the mesorectum. Neoadjuvant radiotherapy is indicated for locally advanced operable tumors [1].

The locoregional treatment constituted by the association of radiotherapy and surgery can lead to sexual and urinary disorders. We are evaluating this type of complication in the management of rectal cancers at CHU, The Dantec of Dakar.

\section{Patients and Methods}

\subsection{Study Framework}

This study was conducted at the Joliot Curie Institute of Dakar, which includes a radiotherapy unit, a surgery unit and a chemotherapy unit.

\subsection{Type of Study}

It is a descriptive retrospective study of 50 patients treated by surgery and/or radiotherapy for rectal cancer from January 2008 to December 2015.

\subsection{Objective of the Study}

The objective is to assess sexual complications and the influencing factors.

\subsection{Selection Criteria}

We included during this period all consecutive patients with histologically confirmed rectal cancer.

\subsection{Data Collection and Analysis}

We used the following documents: patient medical records, hospitalization, operating room and histopathology laboratory records.

The data collected were entered into Excel and processed using the SPSS 21 software.

\section{Results}

The 50 patients, 22 men and 28 women (Sex Ratio: 0.78), are 55.7 years old on average. The dominant clinical signs are rectorragies, found in $66.0 \%$ of cases. Endoscopy is performed in $94.0 \%$ of cases, showing an ulcer-budding appearance in $84.0 \%$ of cases. The tumor is localized to the lower rectum in 33 patients (66.0\%). The predominant histologic type is lieberkunian adenocarcinoma (82.0\%). Stage III is the most represented (70.0\%).

On the therapeutic level, thirty-two patients (64.0\%) benefited from treatment by conventional $2 \mathrm{D}$ radiotherapy with 2 beams associated or not with chemotherapy: Eight (08) by exclusive radiotherapy (RTE) preoperative, Twenty (20) by concomitant radiochemotherapy (RCT) preoperative, one (01) RTE preoperative and chemotherapy (CT) postoperative, two (02) by RTE postoperative and 
one (1) RCT postoperative

The total dose of 46 Gy (23 fractions of 5 days per week) is found in 22 patients; 30 Gy in 10 sessions in 9 cases and 16 Gy in 10 fractions in 1 case.

Conventional splits had an average spread of 30.14 days and hypofractions of 13.24 days. After irradiation, we note a complete response in $28.0 \%$ of patients; partial response in $8.0 \%$, progression in $16.0 \%$ of patients and stabilization in $4.0 \%$ of patients.

The surgery performed is abdominal-perineal amputation in $58.0 \%$ of cases and resection with sphincterial conservation in $42.0 \%$ (anterior resection in 17 patients and total proctectomy in 4 patients). The surgical technique influenced the sexual functional result (Table 1).

Sexual disorders are more important after radiotherapy compared to non-irradiated patients: $31.3 \%$ vs $5.6 \%(\mathrm{p}=0.035)$ (Table 2$)$.

At 6 months, the evolution is marked by persistent sexual problems in $63.8 \%$ of cases and urinary dysfunction in $4 \%$ of cases.

Patient follow-up ranged from 0 to 42.83 months with an estimated mean of $34.9 \pm 3.37(95 \% \mathrm{CI}=[28.270-41.465])$.

From 3 months the survival, which was $0.978 \pm 0.022$, decreases to $0.878 \pm$ 0.052 at the $6^{\text {th }}$ month and stabilizes until the 26 th month. It is $0.658 \pm 0.194$ and was obtained from the $28^{\text {th }}$ month (Figure 1 ).

\section{Discussion}

The average age of our patients is 55.7 years. It ranges from 65 to 75 years in Western literature [2]. This young age is one more argument for studying sexual disorders after treatment.

We can improve the pre-therapeutic assessment of our patients. Computed tomography is performed for $78 \%$ of them. It has a diagnostic accuracy of $55 \%$ to $72 \%$ for tumor and $25 \%$ to $75 \%$ for adenopathies.

Magnetic resonance imaging has better resolution for mesorectum. We have done it for $30 \%$ of our patients. According to Beets-Tan et al., an IRM distance of $5 \mathrm{~mm}$ between the tumor and fascia led to a resection margin of $1 \mathrm{~mm}$ on

Table 1. Sexual disorders by type of anastomosis and stoma

\begin{tabular}{ccccc}
\hline Sexual disorders & $\begin{array}{c}\text { High colorectal } \\
\text { anastomosis (7) }\end{array}$ & $\begin{array}{c}\text { Low colorectal } \\
\text { anastomosis (10) }\end{array}$ & $\begin{array}{c}\text { Colo anale } \\
\text { anastomosis (4) }\end{array}$ & $\begin{array}{c}\text { Final colostomy } \\
\text { (29) }\end{array}$ \\
\hline Ejaculation disorder & 0 & 1 & 0 & 10 \\
Erectile dysfunction & 0 & 1 & 0 & 10 \\
\hline
\end{tabular}

Table 2. Sexual disorders by radiation therapy.

\begin{tabular}{cccccc}
\hline Sexual disorders & RTE (32) & Without RTE (18) & p & OR & IC to 95\% \\
\hline Ejaculation disorder & $10(31.3 \%)$ & $1(5.6 \%)$ & 0.035 & 7.727 & {$[0.899-66.394]$} \\
Erectile dysfunction & $10(31.3 \%)$ & $1(5.6 \%)$ & 0.035 & 7.727 & {$[0.899-66.394]$} \\
\hline
\end{tabular}


histological examination and better predicted resection margins [3].

The German Rectal Cancer Group compared a pre-operative or adjuvant RCT approach. The first approach offered a benefit in terms of local control (6\% versus $13 \%$ ) [4]. We have 20 cases of pre-operative RCT, while only one case has had post-operative RCT.

Abdominal amputation is performed in $58 \%$ of cases and sphincter conservation surgery in $42 \%$. The sphincterial conservation rate of different foreign series is given in Table 3.

\subsection{Sexual Disorders}

Very few studies have specifically studied sexual disorders in women. Age is associated with decreased sexual activity in both the male and female population. Post-operative sexual activity is $86 \%$ among those under 60 years and $46 \%$ after 60 years [5] [6] [7]. We find a rate of sexual disorders in men lower than that found in foreign series (Table 4).

According to Lange, the risk of nerve damage during dissection in the narrow male pelvis is higher than in women. However, the instruments used to assess sexual disorders are different between men and women, so comparison between the two sexes is difficult [8].

The rate of sexual impotence after rectal surgery varies from 5\% to $92 \%$ [9] [10]. We found a significant difference depending on the type of surgery. Thus, $66 \%$ of our patients had functional sexual disorders after prior resection of the rectum. They were more important after abdominal-perineal amputation. Our results are consistent with the data in the literature [11]. However, the preservation of the autonomic nervous system is not specified in our patients' operating reports.

Like Bonnel et al., Heriot et al., we note a deleterious effect of radiotherapy on sexual function [7] [12]. A Dutch study including 990 patients reported a decline in sexual activity in both sexes after radiotherapy [13].

The efficacy of sildenafil on these disorders has been described. Erectile function is improved in $80 \%$ of patients compared to $17 \%$ with placebo [14].

Finally, the insertion of a penile prosthesis is effective but irreversible and

Table 3. Sphincter conservation rates in our series and in the literature [23].

\begin{tabular}{cccccc}
\hline Our series & $\begin{array}{c}\text { Mohuiddin } \\
\text { et al. (121) }\end{array}$ & $\begin{array}{c}\text { Rouanet } \\
\text { et al. (143) }\end{array}$ & $\begin{array}{c}\text { Crane } \\
\text { et al. (34) }\end{array}$ & $\begin{array}{c}\text { Rengan } \\
\text { et al. (138) }\end{array}$ & $\begin{array}{c}\text { Kim } \text { et al. } \\
\text { (91) }\end{array}$ \\
\hline $42 \%$ & $90 \%$ & $70 \%$ & $50 \%$ & $77 \%$ & $35 \%$ \\
\hline
\end{tabular}

Table 4. Sexual disorders in our series and in the literature [23].

\begin{tabular}{cccccc}
\hline Sexual disoders & Our series & $\begin{array}{c}\text { Jayne } \\
\text { et al. }\end{array}$ & Hendren & Stamopoulos & Bittorf et al. [17] \\
\hline M & $47.8 \%$ & $50 \%$ & $43 \%$ & $66 \%$ & $69.5 \%$ \\
F & $44.4 \%$ & - & $39 \%$ & - & $16.7 \%$ \\
\hline
\end{tabular}


invasive. It must be proposed only after failure of medical means.

The therapeutic approach to sexual dysfunction in women, including libido disorders after rectal surgery, is empirically based on sex therapy and psychotherapy [15] [16].

Short-term estrogen therapy is recommended for genital trophicity disorders [17].

\subsection{Urinary Problems}

Post-operatively, we observed respectively that $2 \%, 6 \%$ and $8 \%$ of our patients had urinary problems in the form of acute transient urine retention, urinary incontinence, and urinary burning.

In the literature, the rate of urinary disorders varies between $30 \%$ and $70 \%$ [18]. According to Fish, the risk of urinary dysfunction increases with age [9]. Our small numbers do not allow us to compare our results with those of the literature. Two studies have found that urinary disorders are all the more important when the anastomosis is closer to the anus [19] [20]. We have not found this influence of the type of anastomosis.

There is little consensus on the duration and type of bladder drainage to be implemented after rectal cancer surgery. The recommendations of the French Society of Digestive Surgery underline the interest of the supra pubic catheter in case of tumor of the lower rectum or if a bladder drainage of more than five days is envisaged [21].

The rate of urinary disorders we have observed is low. At 3 months, this rate is 1\%. Del Rio et al., describe $31 \%$ of urinary disorders at 3 months [22].

We do not note any influence of radiotherapy on urinary function contrary to Bonnel and Heriot who report a deleterious effect on this function [7] [12].

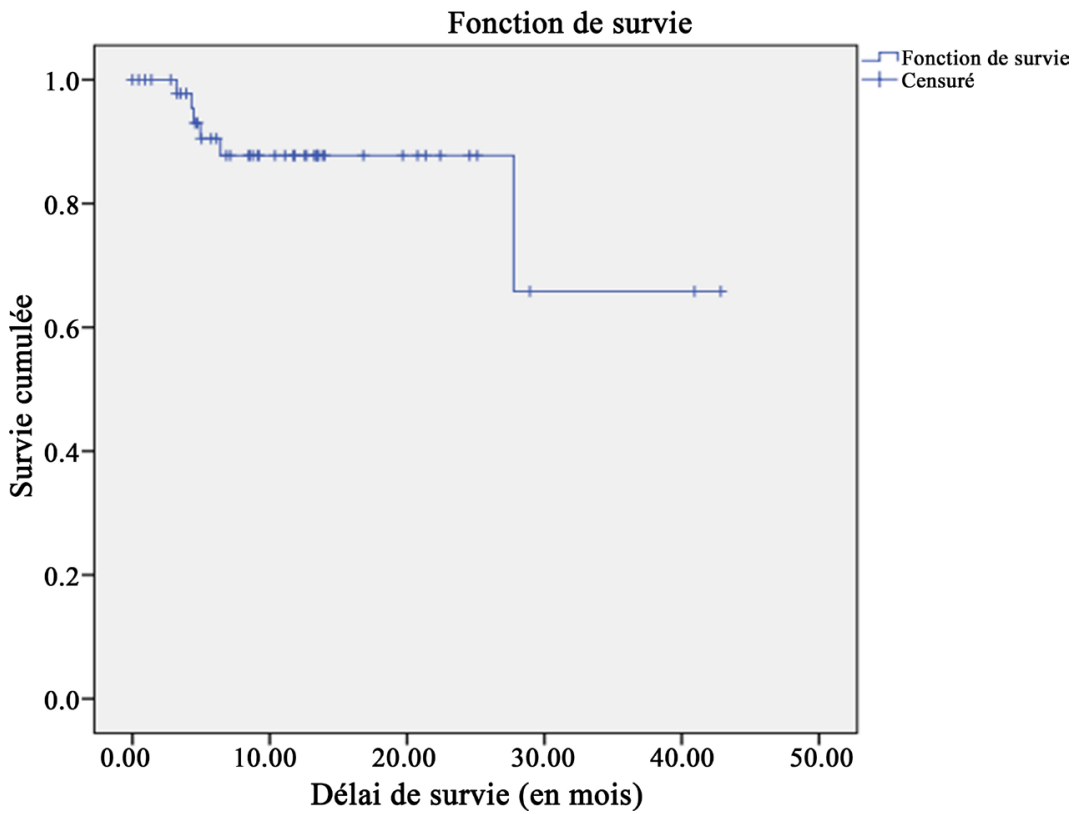

Figure 1. Survie globale. 
The persistence of urinary disorders in our series is $4 \%$ to 6 months postoperative, higher than the data in the literature 0 to $2.8 \%$ [19].

We have an overall survival rate at 5 years of $10 \%$, lower than the data in the literature [20]. This could be explained by the fact that the majority of our patients are received in advanced stages and the preoperative radiochemotherapy indicated to reduce the stage often results in difficult, often incomplete R1-type excision, source of recurrence and mortality in the medium term.

\section{Conclusion}

The reduction of sexual and urinary complications in the treatment of rectal cancers and their better evaluation and management will only be achieved through wider transdisciplinary consultation. It will also require the accessibility of modern irradiation methods.

\section{Conflicts of Interest}

The authors declare that they have no conflicts of interest in relation to this article.

\section{References}

[1] Valentini, V., Aristei, C., Glimelius, B., et al. (2009) Multidisciplinary Rectal Cancer Management: 2nd European Rectal Cancer Consensus Conference (EURECA-CC2). Radiotherapy and Oncology, 92, 148-163. https://doi.org/10.1016/j.radonc.2009.06.027

[2] Boutron Ruault, M.C. and Laurant Puig, P. (2005) Epidemiologie, cancerogenese, facteurs de risqué, prevention et depistage du cancer colo-rectal Traite de gastroenterologie, deuxieme edition. Flammarion, 538-550.

[3] Beets-Tan, R.G., Beets, G.L., Vliegen, R.F., et al. (2001) Accuracy of Magnetic Resonance Imaging in Prediction of Tumor-Free Resection Margin in Rectal Cancer Surgery. The Lancet, 357, 497-504. https://doi.org/10.1016/S0140-6736(00)04040-X

[4] https://orbi.ulg.ac.be/bitstream/2268/164040/1/LA\%20RADIOTH\%C3\%89RAPIE\% 20DANS\%20LE\%20CANCER\%20DU\%20RECTUM.pdf

[5] Havenga, K., Enker, W.E., Mc Dermott, K., et al. (1996) Male and Female Sexual and Urinary Function after Total Mesorectal Excision with Automatic Nerve Preservation for Carcinoma of Rectum. Journal of the American College of Surgeons, 182, 495-502.

[6] Droupy (2005) Encyclopedie Medico-Chirurgicale. Elsevier, Paris. Urologie.

[7] Heriot, A.G., Tekkis, P.P., Fazio, V.W., et al. (2005) Adjuvant Radiotherapy Is Associated with Increased Sexual Dysfunction in Male Patients Undergoing Resection for Rectal Cancer: A Predictive Model. Annals of Surgery, 242, 502-510.

[8] Canada, A.L., Neese, L.E., Sui, D., et al. (2005) Pilot Intervention to Enhance Sexual Rehabilitation for Couples after Treatment for Localized Prostate Carcinoma. Cancer, 104, 2689-2700. https://doi.org/10.1002/cncr.21537

[9] Larissa, K.F., Douglas, W., Bruce, M., et al. (2003) The Impact of Radiation on Functional Outcomes in Patients with Rectal Cancer and Sphincter Preservation Seminars in Radiation. Oncology, 13, 469-477.

https://doi.org/10.1016/S1053-4296(03)00051-1 
[10] Ho, V.P., Lee, Y., Stein, S.L., et al. (2011) Sexual Function after Treatment for Rectal Cancer: A Review. Diseases of the Colon \& Rectum, 54, 113-125. https://doi.org/10.1007/DCR.0b013e3181fb7b82

[11] Bregendahl, S., Emmertsen, K.J., Lindegaard, J.C., et al. (2015) Urinary and Sexual Dysfunction in Women after Resection with and without Preoperative Radiotherapy for Rectal Cancer: A Population-Based Cross-Sectional Study. Colorectal Disease, 17, 26-37. https://doi.org/10.1111/codi.12758

[12] Bonnel, C., Parc, Y.R., Pocard, M., et al. (2002) Effects of Preoperative Radiotherapy for Primary Resectable Rectal Adenocarcinoma on Male Sexual and Urinary Function. Diseases of the Colon \& Rectum, 45, 934-939. https://doi.org/10.1007/s10350-004-6332-8

[13] Marijnen, C.A., Van de Velde, C.J., Putter, H., et al. (2005) Impact of Short-Term Preoperative Radiotherapy on Health-Related Quality of Life and Sexual Functioning in Primary Rectal Cancer: Report of a Multicenter Randomized Trial. Journal of Clinical Oncology, 23, 1847-1858. https://doi.org/10.1200/JCO.2005.05.256

[14] Lindsey, I., George, B., Kettlewell, M., et al. (2002) Randomized, Double-Blind, Placebo-Controlled Trial of Sildenafil (Viagra) for Erectile Dysfunction after Rectal Excision for Cancer and Inflammatory Bowel Disease. Diseases of the Colon \& Rectum, 45, 727-732. https://doi.org/10.1007/s10350-004-6287-9

[15] Zippe, C.D., Nandipati, K.C., Agarwal, A., et al. (2005) Female Sexual Dysfunction after Pelvic Surgery: The Impact of Surgical Modifications. BJU International, 96, 959-963. https://doi.org/10.1111/j.1464-410X.2005.05737.x

[16] Basson, R., Althof, S., Davis, S., et al. (2004) Summary of the Recommendations on Sexual Dysfunctions in Women. The Journal of Sexual Medicine, 1, 24-34. https://doi.org/10.1111/j.1743-6109.2004.10105.x

[17] Keli, Z. (2013) Profil epidemiologique du cancer colorectal dans la region orientale. These Medicale; Fes; No. 22.

[18] Mannaerts, G.H., Schijven, M.P., Hendrikx, A., et al. (2001) Urologic and Sexual Morbidity Following Multimodality Treatment for Locally Advanced Primary and Locally Recurrent Rectal Cancer. European Journal of Surgical Oncology, 27, 108-172. https://doi.org/10.1053/ejso.2000.1099

[19] Benoist, S., Panis, Y., Denet, C., et al. (1999) Optimal Duration of Urinary Drainage after Rectal Resection: A Randomized Controlled Trial. Surgery, 125, 135-141. https://doi.org/10.1016/S0039-6060(99)70256-4

[20] Heald, R.J. (1982) The Mesorectum in Rectal Cancer Surgery: The Clue to Pelvic Recurrence? British Journal of Surgery, 69, 613-616. https://doi.org/10.1002/bjs.1800691019

[21] Mariette, C., Alves, A., Benoist, S., et al. (2005) Perioperative Care in Digestive Surgery: Guidelines for the French Society of Digestive Surgery (SFCD). Annales de Chirurgie, 130, 1847-1824. https://doi.org/10.1016/j.anchir.2004.12.003

[22] Del Rio, C., Sanchez-Santos, R., Oreja, V., et al. (2004) Long-Term Urinary Dysfunction after Rectal Cancer Surgery. Colorectal Disease, 6, 198-202. https://doi.org/10.1111/j.1463-1318.2004.00624.x

[23] Benani, I. (2017) Traitement radiochirurgical des cancers du rectum à l'institut Joliot curie de Dakar: Etude retrospective de 50 cas. Thèse Médecine, $\mathbf{8 8 .}$ 